\title{
Proposta de Infraestrutura Verde em área Litorânea: Um Estudo de Caso em Pontal do Sul - PR
}

Green Infrastructure Proposal in Coastal Regions: A Case Study in Pontal do Sul - PR

Propuesta de Infraestructura Verde em área Litoral: Un Estudio de Caso em Pontal do

$$
\text { Sul }-P R
$$

Bruno Victor Kobiski

Mestre, UFPR, Brasil kobiski@ufpr.br

Jemina de Lima UFPR, Brasil Jhemina.lima@gmail.com

Henrique Ukan UFPR, Brasil henriqueukan@gmail.com

\section{Alexandre Bernardino Lopes} Professor Doutor, UFPR, Brasil ablopesrp@ufpr.br

Talal Suleiman Mahmoud Professor Doutor, UFPR, Brasil talal@ufpr.br

Cintia Miua Maruyama Professor Mestre, UFPR, Brasil cintiamaruyama@ufpr.br 


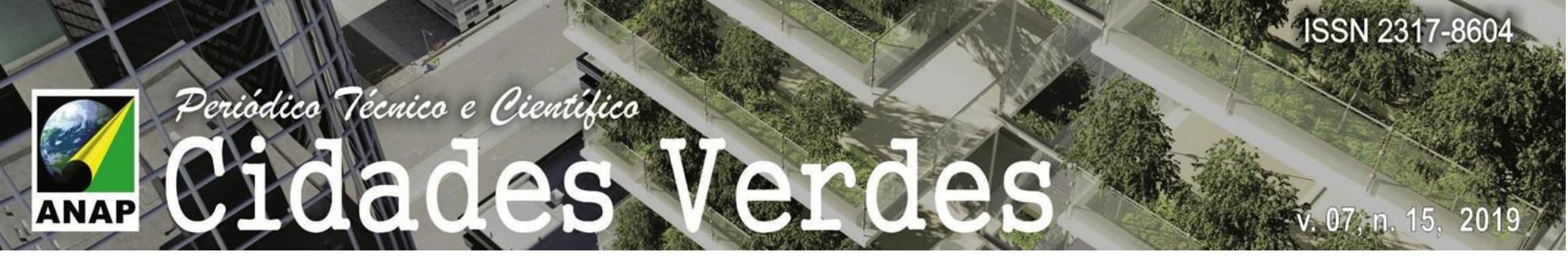

\section{RESUMO}

Pontal do Sul é um balneário de Pontal do Paraná, no estado do Paraná, Brasil, que possui deficiências de infraestrutura urbana. Um projeto de pesquisa e extensão foi coordenado pela Profa Cíntia Miua Maruyama para contribuir com o desenvolvimento desta região. O projeto foi realizado em várias etapas, consistindo em um levantamento topográfico e diagnóstico físico, um levantamento de dados sobre árvores como subsídio de informações e um projeto de mobilidade e paisagismo da orla, além de uma revisão bibliográfica acerca do tema. Para a realização das etapas foram necessárias reuniões com o órgão público municipal, aquisições de imagens e mapas do órgão público estadual e consultas com o Instituto Ambiental do Paraná - IAP. As informações culminaram em um projeto compatibilizado com os padrões existentes, envolvendo o estudo da seção típica da via, que inclui a calçada, ciclovia, a rua, arborização e faixas vegetadas com biovaletas e canteiro pluvial. 0 projeto levou em conta o conforto dos pedestres e a diminuição de ilhas de calor. Todos estes trabalhos tiveram o envolvimento de alunos de graduação e docentes. De modo geral, esta iniciativa proporcionou o contato dos alunos com os assuntos desenvolvidos no trabalho de forma a contribuir para sua formação, no intento de trazer benefícios para a comunidade local com melhoria na circulação de ciclistas, pedestres e na drenagem da região, assim como poderá servir de base para que a Prefeitura elabore o projeto, cumprindo desta forma o papel da transferência de conhecimento da Universidade.

PALAVRAS-CHAVE: Biovaleta. Arborização urbana. Infraestrutura verde

\section{RESUMEN}

Pontal do Sul es un balneario de Pontal do Paraná, en el estado de Paraná, Brasil, que tiene deficiencias de infraestructura urbana. Un proyecto de extensión fue coordinado por la Profa Cintia Miua Maruyama para contribuir con el desarrollo de esta región. El proyecto fue realizado en varias etapas, consistentes en un levantamiento topográfico y diagnóstico físico, un levantamiento de datos sobre árboles como subsidio de informaciones y un proyecto de movilidad y paisajismo de la orilla, además de una revisión bibliográfica acerca del tema. Para realizar las etapas fueron necesarias reuniones con el órgano público municipal, adquisiciones de imágenes y mapas del órgano público estadual y consultas con el Instituto Ambiental do Paraná - IAP. La información culminó en un proyecto involucrando el estudio de la sección típica de la vía, que incluye la calzada, ciclovía, la calle, arborización y franjas vegetales con biovaletas, cantero pluvial y jardín de lluvia. El proyecto tuvo en cuenta la comodidad de los peatones y la disminución de las islas de calor. Los trabajos tuvieron la participación de alumnos de graduación y docentes. Esta iniciativa proporcionó el contacto de los alumnos con los asuntos desarrollados en el trabajo para contribuir a su formación, en el intento de traer beneficios para la comunidad con mejoría en la circulación de ciclistas, peatones y en el drenaje de la región, así como puede servir de base para que la municipalidad elabore el proyecto, cumpliendo el papel de la transferencia de conocimiento de la Universidad.

PALAVRAS-CHAVE: Biovaleta. Arborización urbana. infraestructura verde.

\section{ABSTRACT}

Pontal do Sul is a neighborhood of Pontal do Paraná, in the state of Paraná, Brazil, which has deficiencies in urban infrastructure. A research and extension project was coordinated by Prof Cíntia Miua Maruyama to contribute to this region development. The project was carried out in several stages, consisting of a topographic survey and physical diagnosis, a data collection on trees as information source and a mobility and landscaping project, as well as a bibliographical review on the theme. In order to carry out the steps, meetings with the municipal public agency, image acquisition and maps of the state public agency and consultations with the Instituto Ambiental do Paraná (IAP) were required. The information culminated in a project compatible with the existing standards, involving the study of the typical section of the road, which includes sidewalk, bicycle lane, street, afforestation and vegetated bands with biovallets, rainforest and rain garden. The project took into account the comfort of pedestrians and the reduction of heat islands. All these works had the involvement of undergraduate students and teachers. In general, this initiative provided the students' contact with the subjects developed in the work in order to contribute to their formation, in the attempt to bring benefits to the local community with improvement in the circulation of cyclists, pedestrians and in the drainage of the region, as well as can serve as a basis for the City Hall to elaborate the project, fulfilling the role of the University in knowledge transfer.

PALAVRAS-CHAVE: Bioswale. Urban afforestation. Green infrasctructure 


\section{Introdução}

A expansão urbana aliada a um adensamento populacional sem ordenação é um dos principais problemas relacionados ao desenvolvimento territorial sustentável. Com o advento da tecnologia, as cidades se tornaram mais adensadas, absorvendo populações que antes habitavam áreas rurais. De acordo com o IBGE (2010), 80\% da população vive em áreas urbanas, sendo que este número poderá chegar a até $91 \%$ nas próximas duas décadas. Esta condição favorece a ocupação de áreas não destinadas à urbanização e áreas ambientalmente sensíveis, quando a municipalidade não consegue adequar seu planejamento de desenvolvimento urbano às novas demandas.

Nos dias atuais, um novo modelo de desenvolvimento urbano vem sendo aplicado. Este modelo traz como conceito principal a noção de que meio ambiente e cidades podem atuar sinergicamente, propondo intervenções urbanísticas que exploram profundamente as relações do ambiente com seus aspectos naturais, evidenciando a importância das paisagens naturais na manutenção da qualidade de vida de uma comunidade. A esta prática é dado o nome de Infraestrutura Verde (BONZI,2015).

Diversas tipologias paisagísticas são comumente aplicadas dentro do conceito de infraestrutura verde, como jardins de chuva, canteiros pluviais, biovaletas, lagoas pluviais, alagados, cisternas, telhados verdes, pavimentos drenantes, reabilitação de córregos entre outros.

A cidade de Portland, no estado americano de Maine, é modelo em relação à gestão de recursos hídricos no âmbito do planejamento urbano e projetos de infraestrutura, contribuindo para estudos na área e fornecendo diretrizes de construção que podem se adequar a qualquer condição climática, topográfica ou geográfica (PORTLAND STORMWATER MANAGEMENT MANUAL, 2016).

No Brasil, a Infraestrutura Verde ainda não é uma temática sobre a qual se debruçam muitas reflexões em torno da gestão ambiental e territorial urbana, sendo tratada ainda de forma muito incipiente e fragmentada tanto no meio social, como técnico e organizacional. Segundo Schutzer (2014), esta condição se dá pelo pragmatismo cultural referente à forma de construir e planejar cidades, assim como pelo interesse de entidades e pessoas com alto poder de influência.

De acordo com o Caderno de Referência para Elaboração de Planos de Mobilidade do Ministério das Cidades (2015), é necessário um planejamento de curto, médio e longo prazo para orientar e coordenar esforços, planos e investimentos, garantindo um desenvolvimento urbano com igualdade social, eficiência administrativa e desempenho ambiental.

Pontal do Paraná é uma cidade litorânea do estado do Paraná, caracterizada por uma infraestrutura urbana precária, insuficiência de saneamento básico e problemas relacionados à poluição ambiental e mobilidade. A cidade é relativamente jovem perante outros municípios do estado, tendo sido criada em 20 de dezembro de 1995. Suas primeiras influências antrópicas coincidem com os fluxos de colonização do estado no século XVII. As proximidades geográficas com o município de Paranaguá fizeram com que este último tivesse influência política na vida pública dos pontalenses até sua emancipação no final do século XVIII.

A economia da cidade se baseia na pesca e eventos como a festa da Tainha, Festa do Camarão, Camacho, turismo náutico e de balneário entre outros. Dos $50 \mathrm{~km}$ de praias disponíveis no litoral 


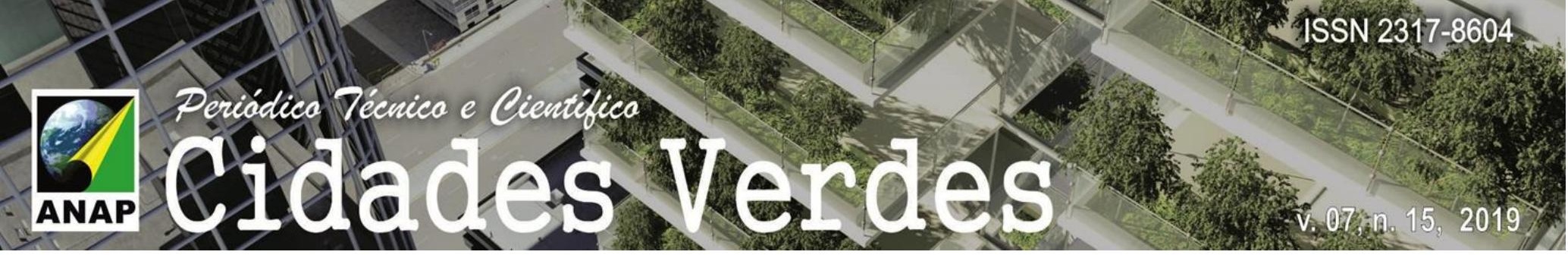

do Paraná, 23 km estão dentro dos limites de Pontal do Paraná. O município dista 96,50 km da capital paranaense e é delimitado pelo Oceano Atlântico à leste, a Baía de Paranaguá à norte, Paranaguá à oeste e Matinhos a sul. A grande extensão da orla proporciona diversos atrativos turísticos, que impulsionam o município em direção ao desenvolvimento (PONTAL DO PARANÁ, 2018).

Figura 1 - Município de Pontal do Paraná

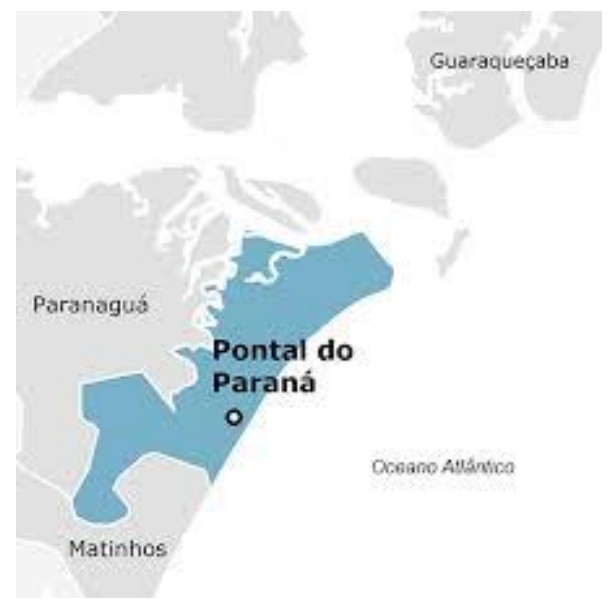

Fonte: IPARDES (2019)

Segundo dados do IBGE (2018), a população do último censo, em 2010, era de 20920 pessoas, sendo a estimativa para o ano de 2018 de 26636 pessoas. Esta classificação denota uma cidade pouco povoada, aliada a uma densidade demográfica relativamente baixa, de 104,67 hab $/ \mathrm{km}^{2}$ 29 o no ranking estadual.

Ainda segundo dados do IBGE, Pontal do Paraná possui um salário médio mensal dos trabalhadores de 3,0 salários mínimos, 9o lugar no ranking do estado, um PIB per capita de R\$ 17483,32 e um índice de desenvolvimento humano municipal de 0,738, índice considerado mediano. Possuem classificação "alta" as regiões com IDH acima de 0,800 .

Em relação aos dados urbanos, a cidade possui 69,7\% (IBGE, 2010) de esgotamento sanitário adequado, um índice relativamente importante, que contribui para o aumento da qualidade de vida e da saúde, uma vez que se trata de uma cidade litorânea, com canais de drenagem que desaguam diretamente no mar. Somam-se a isto uma taxa de arborização de $83,6 \%$ e uma taxa urbanização de vias públicas de $4,5 \%$.

De acordo com os levantamentos sobre a cidade de Pontal do Paraná, foram traçados objetivos deste trabalho, que incluíram a idealização e realização do projeto da avenida beira-mar, contendo equipamentos urbanos de auxílio da drenagem e mobilidade como ciclovias, espaços verdes, pisos permeáveis e biovaletas.

Este artigo, portanto, se trata do relato do projeto de extensão universitária da Universidade Federal do Paraná - UFPR, que atuou na criação de diretrizes de mobilidade urbana, incorporando os conceitos de Infraestrutura Verde na cidade de Pontal do Paraná. Os trabalhos realizados envolveram levantamento de dados, como levantamento topográfico, pesquisa e 


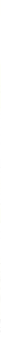

análise em mapas existentes e estudo de tipologias de Infraestrutura Verde e vegetais para propor um projeto modelo de avenida beira-mar com relação às calçadas, ciclovias e faixas vegetadas.

\section{Materiais e Métodos}

\subsection{Coleta de Dados}

A coleta de dados se deu com base em levantamentos de campo e também mapas cedidos pelo Paranacidade. Os mapas foram confrontados com levantamentos feitos por drone e também com imagens disponíveis na web.

Foram utilizados os dados constantes em arquivos em AutoCAD cedidos pelo PARANACIDADE, para avaliação geográfica e definição do escopo de trabalho e área de intervenção, assim como informações do Google Earth (2018). Também foi realizado vôo de drone na área de estudo para auxiliar no reconhecimento, avaliação da região e auxiliar a elaboração do projeto.

Além disso foi realizado um levantamento topográfico, para levantamento e posicionamento de postes de iluminação e eletricidade, verificação do relevo e das condições locais da área de intervenção, utilizando um aparelho de GPS marca GARMIN, em coordenadas WGS 84, para conferir uma aproximação do projeto com as características geográficas da região.

A seguir, um levantamento de campo para reconhecimento das condições de infraestrutura instaladas foi realizado, de forma a proporcionar informação suficiente para definir diretrizes de projeto, de acordo com os potenciais naturais do local. O levantamento disponibilizou a localização precisa de postes, a largura das calçadas e caixas de via, a extensão do projeto e também o nível de desenvolvimento urbano nos locais analisados. Foram também utilizadas informações do Instituto Ambiental do Paraná sobre recursos florestais a fim de realizar uma pré-seleção de espécies indicadas para plantio na área de intervenção do projeto.

\subsection{Desenvolvimento do Projeto}

O projeto foi idealizado com base nas informações adquiridas e resultou no desenho da seção viária que compreende: as faixas de rolamento, estacionamento de veículos, área para barracas para venda de produtos de artesãos locais, calçadas, ciclovias, projeto de arborização, paisagismo e biovaletas.

A biovaleta foi detalhada, de acordo com as especificações necessárias, devido sua complexidade e restrições de utilização. As diretrizes de desenvolvimento seguiram o Stormwater Management Manual - SWMM (CITY OF PORTLAND, 2016). Este manual proporcionou os parâmetros de projeto.

Foram consideradas, a largura mínima da biovaleta, profundidade, inclinação longitudinal, inclinação lateral, propriedades do extravasor, tipo de encanamento, características da camada drenante, do substrato e da vegetação, a aplicação de manta geotêxtil, espaçamento da caixa de checagem entre outros. 


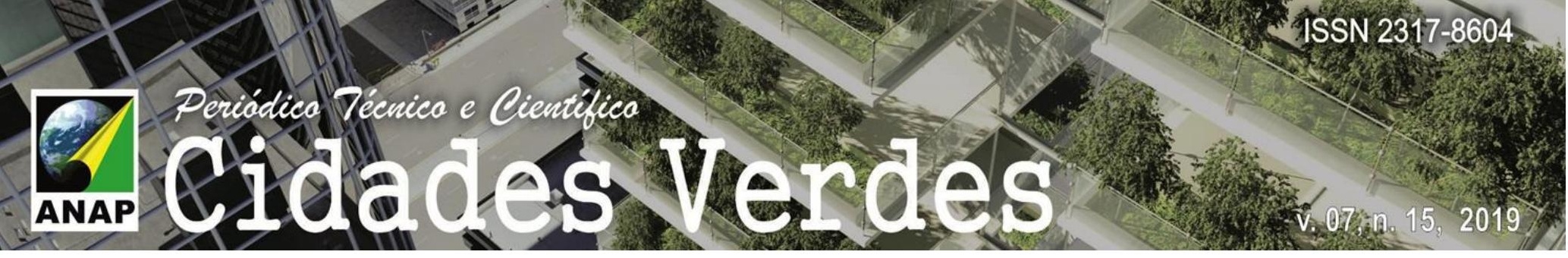

As características da biovaleta levaram em consideração a topografia local, a inclinação da área de intervenção, a profundidade do lençol freático e as características do solo em relação à permeabilidade. A abordagem utilizada, de acordo com o SWMM, foi a simplificada, onde, mesmo considerando parâmetros generalistas, ainda foram feitas adaptações significativas de acordo com as informações disponíveis do município.

As informações foram transcritas em projeto que poderá ser aplicado em toda a extensão da área de intervenção, e poderá servir de modelo para aplicação em outras cidades litorâneas, de acordo com as restrições climáticas, urbanas e de relevo.

\section{Resultados e Discussão}

Os levantamentos utilizados para demarcação da área de intervenção resultaram na Figura 2, que delimita geograficamente as características do local. A área da figura corresponde ao balneário Pontal do Sul, na cidade de Pontal do Paraná.

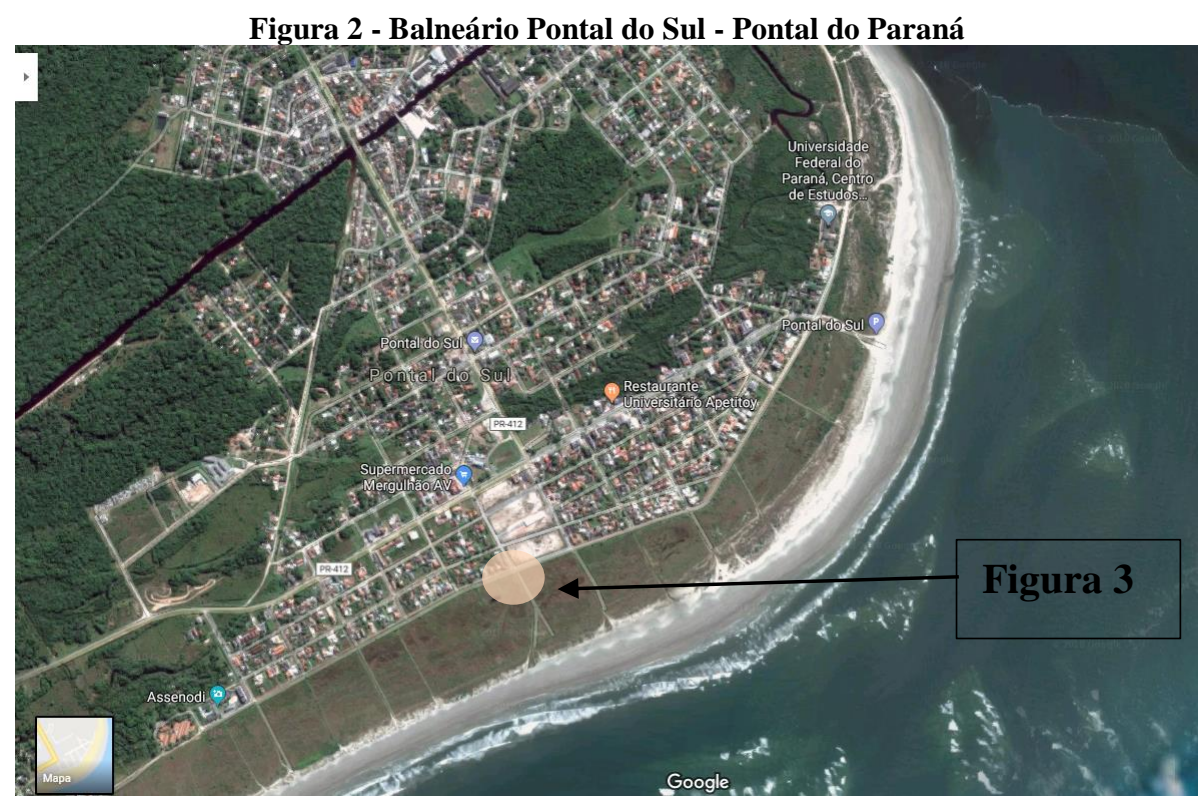

Fonte: Google Earth(2018)

O local carece de infraesturura, porém há grande potencial de urbanização, assim omo demonstra a figura abaixo 

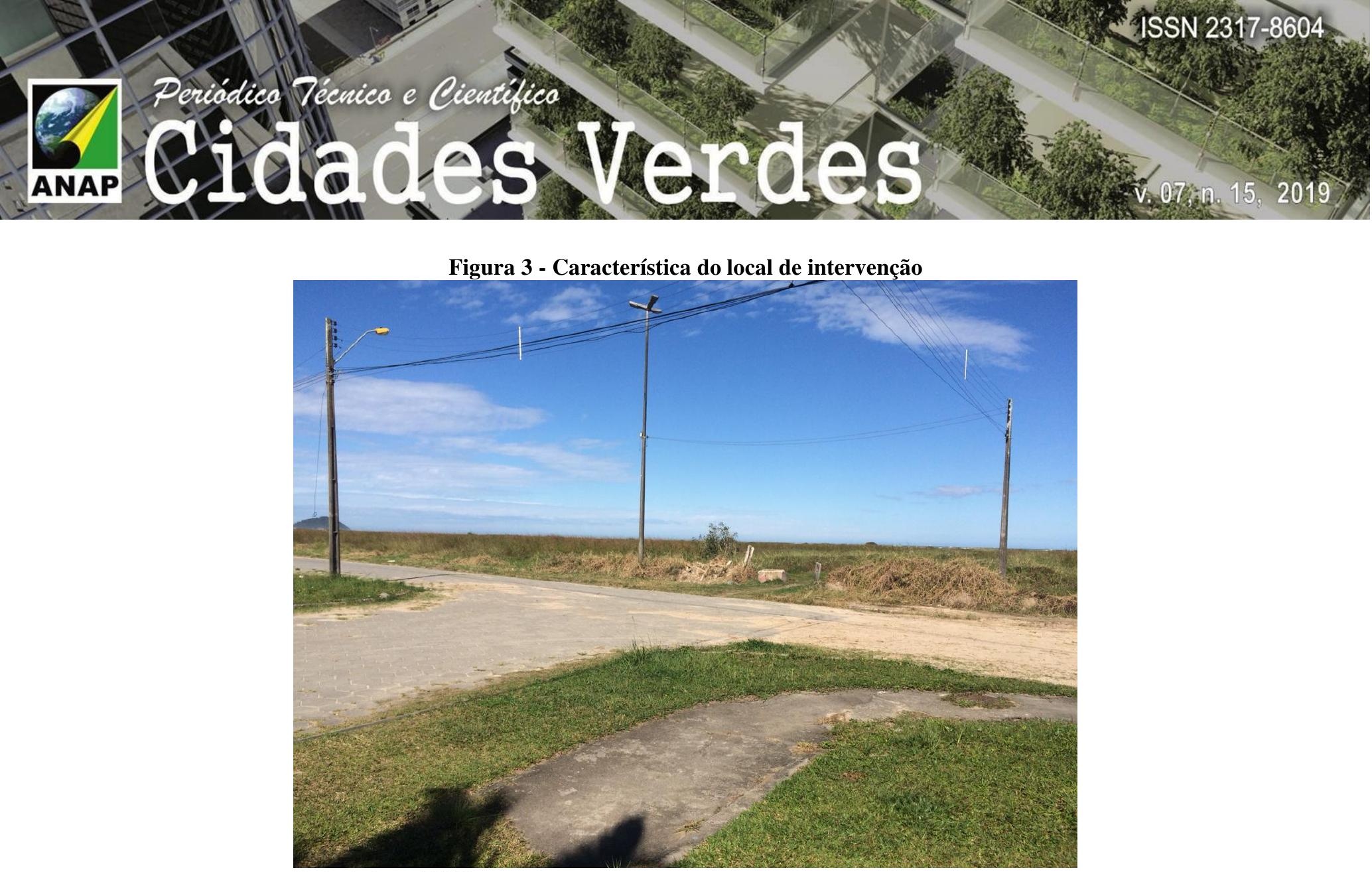

Fonte:Autores (2018)

A demarcação da área de intervenção pode ser observada na figura 4, abaixo, pela faixa em amarelo. Os limites laterais do projeto são a faixa de restinga, que envolve toda a extensão do projeto e a área urbana, já os longitudinais são a Rua das Encantadas e a Rua das Orquídeas.

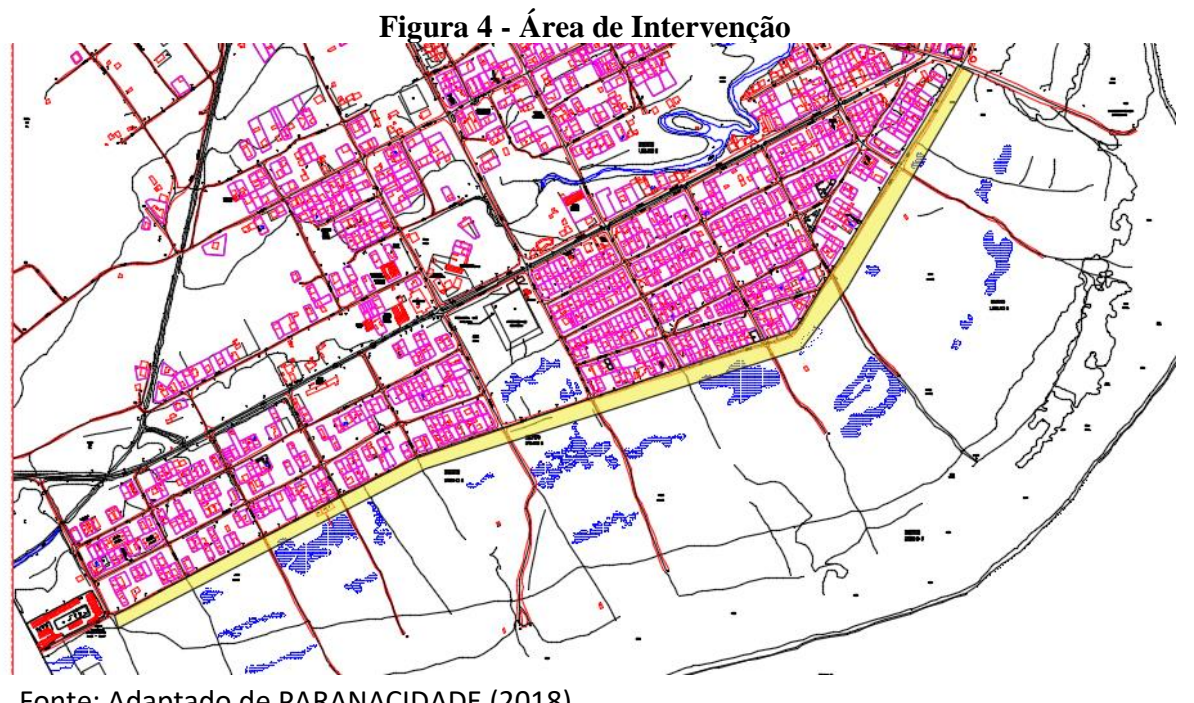

Fonte: Adaptado de PARANACIDADE (2018)

Para que fosse definida a faixa passível de intervenção na Orla de Pontal do Sul, sem que ocorressem conflitos com o Parque Natural Municipal Restinga existente na área foram realizadas diversas reuniões com os técnicos do governo municipal local. Isto levou a definição que a largura total da seção viária deveria variar entre 24 a $30 \mathrm{~m}$, compreendendo desde o limite 


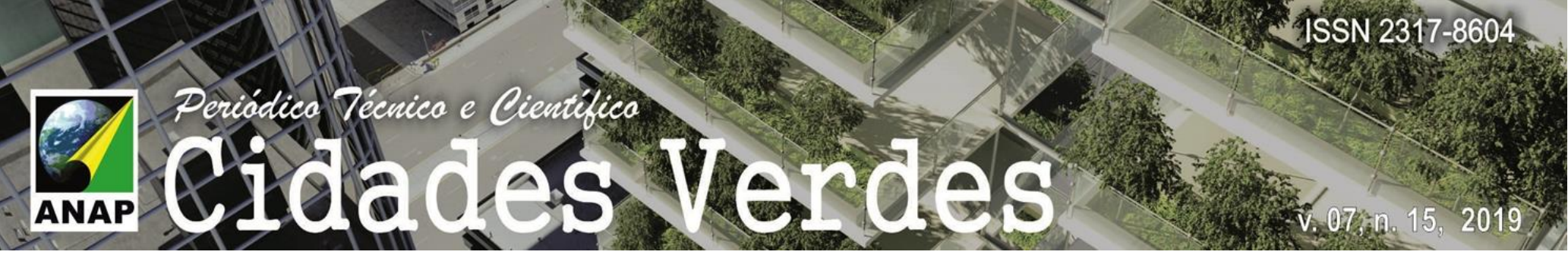

do alinhamento predial até o início da restinga. A partir destas prerrogativas a seção viária foi desenhada e ocupou a largura total de $28 \mathrm{~m}$.

A definição da largura das faixas de rolamento, de estacionamento de veículos e do pavimento asfáltico foi sugerida pela Prefeitura, seguindo o padrão existente no Município. Da mesma, forma foi solicitado pelo poder público municipal que fosse preservada uma faixa sem área de estacionamento para permitir a manobra de carros que fazem a conversão de ruas que seguem sentido perpendicular à orla (Figura 6). Também foi houve o pedido da previsão da instalação de barracas para comércio de artesãos locais.

O projeto considerou o plantio de arborização de forma extensiva, de modo a permitir o sombreamento de pavimentos, pedestres e ciclistas e também para permitir uma otimização nos processos de drenagem e ciclo das águas. As árvores ajudam a diminuir a quantidade de água que vai para os rios e canais de drenagem, pois capturam a água da chuva em suas folhas, galhos e troncos, permitindo uma absorção mais lenta desta água além de colaborar para os processos de infiltração no solo. Para a especificação das espécies foram consideradas as que ocorrem na região (peito de pomba - de porte médio), a partir de consulta com a IAPAR de Morretes/PR, e também observando o seu local de plantio e porte, de modo que em locais onde há rede de eletricidade e fiação foram indicadas espécies de pequeno porte (hibisco).

Com relação à ciclovia, esta foi definida como bidirecional e pavimento de concreto.

A escolha do tipo de pavimento se refere ao fato do concreto emitir menor quantidade de calor do que o pavimento asfáltico, devido à sua coloração mais clara, desta forma ajuda a criar uma ambiência mais confortável aos usuários e colaborar com a diminuição dos efeitos das ilhas de calor urbanas (GARTLAND, 2010). A definição da largura da ciclovia foi baseada nas recomendações do Geipot (2001) e de Mascaró, Mascaró e Freitas (2008), o que resultou numa largura total de $2,50 \mathrm{~m}$.

Foi escolhida a abordagem simplificada para o projeto da biovaleta, sendo estimadas características generalistas para atender uma demanda bastante diversificada de índices pluviométricos. O modelo operacional do projeto foi delimitado como tendo a função de escoar as águas advindas das calçadas e ciclovias anexas até um ponto de descarga aprovado, diminuindo a carga hidráulica nas drenagens pluviais à jusante pela retenção das águas de chuva.

Esta forma de operação foi escolhida em contraste com a drenagem para o solo, devido as características do solo, que possui índices de infiltração bastante satisfatórios, mas que também se encontra muito próximo ao mar. O lençol freático possui, na faixa de implantação do projeto, uma grande variação de profundidade, se encontrando muito próximo à superfície nos momentos em que a maré está alta.

Se o lençol freático se aproximar da camada drenante, a biovaleta perde eficiência por não conseguir infiltrar adequadamente a carga hidráulica presente (CITY OF PORTLAND, 2016). Portanto, a influência da maré no lençol freático foi decisiva para a escolha de isolar o sistema com uma manta geotérmica impermeável. Assim, a biovaleta passou a ter caráter de diminuir a velocidade do escoamento de águas pluviais, e não de infiltração. 


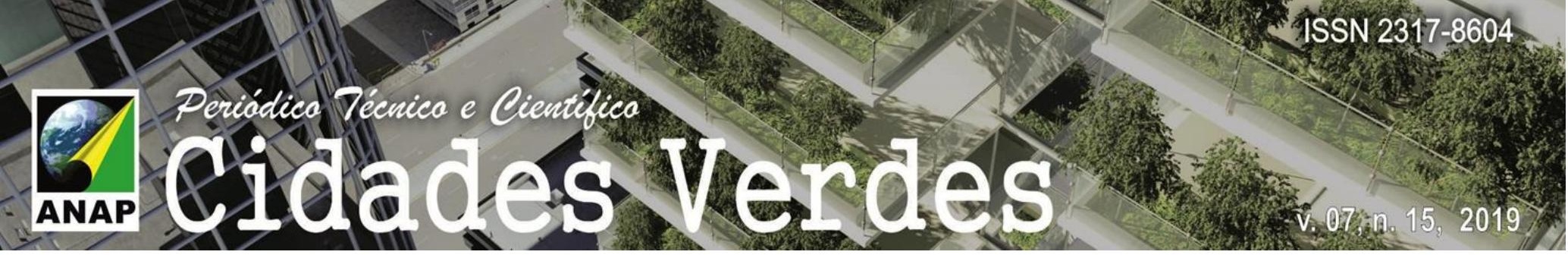

A largura mínima estipulada foi de 3 metros, com inclinação máxima de 3:1 em direção ao centro de 0,6 metros de base plana. A inclinação longitudinal máxima foi também estipulada como sendo de $6 \%$, seguindo o modelo simplificado de projeto (CITY OF PORTLAND , 2016), afim de evitar carreamento de substrato ao longo da biovaleta.

No fundo, deverá haver largura mínima de 0,6 m. A profundidade máxima, contando desde a superfície até o ponto de descarga, deverá ser de $80 \mathrm{~cm}$.

O extravasor deverá conectar diretamente em uma rede de drenagem, sendo protegido contra sedimentos e detritos por meio de uma grelha ou filtro. O encanamento pdoe ser ser de ferro fundido ou de PVC 4", sendo recomendável o de PVC devido à salinidade decorrente da região ser litorânea. Também foram definidas caixas de checagem a cada 100 metros, ou 3 metros onde houver inclinação maior que $4 \%$.

A camada drenante deverá possuir $23 \mathrm{~cm}$ no máximo, sendo constituída de até $7,5 \mathrm{~cm}$ de cascalho na separação com o substrato e $15,5 \mathrm{~cm}$ de seixo rolado, logo abaixo.

Para a vegetação acima do substrato, as espécies escolhidas são mostradas na tabela abaixo.

Quadro 1 - Espécies escolhidas para plantiona biovaleta

\begin{tabular}{|l|c|c|}
\hline \multicolumn{1}{|c|}{ Nome Científico } & $\begin{array}{c}\text { Nome } \\
\text { Popular }\end{array}$ & Classe \\
\hline Lantana camara & Lantana & Arbusto \\
\hline Chlorophytum comosum & Gravatinha & Herbácea \\
\hline Duranta erecta aurea & Pingo de Ouro & Arbusto \\
\hline
\end{tabular}

Fonte: Autores (2018)

O projeto prevê distribuição de herbáceas com quantidade mínima de 85 unidade a cada 10 metros quadrados ou 80 herbáceas e 4 arbustos pequenos, na mesma área.

Toda a área da biovaleta deverá ser preenchida com vegetação. A Figura 5 demonstra uma seção da biovaleta. 


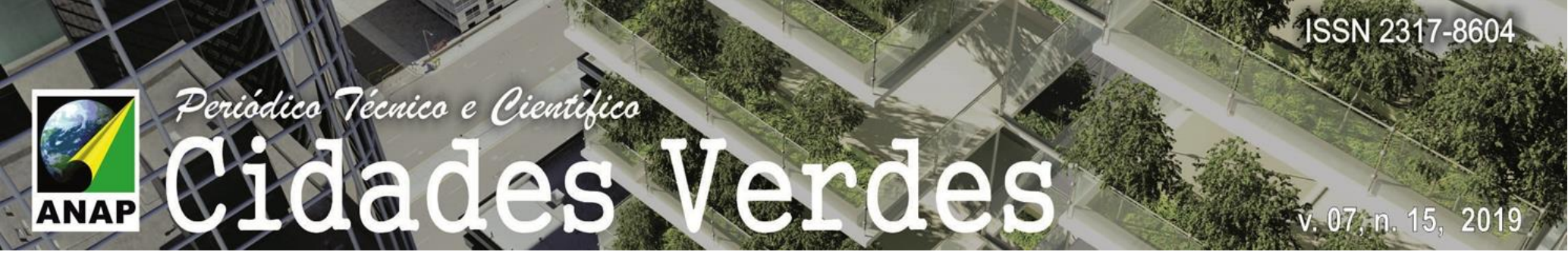

Figura 5 - Biovaleta

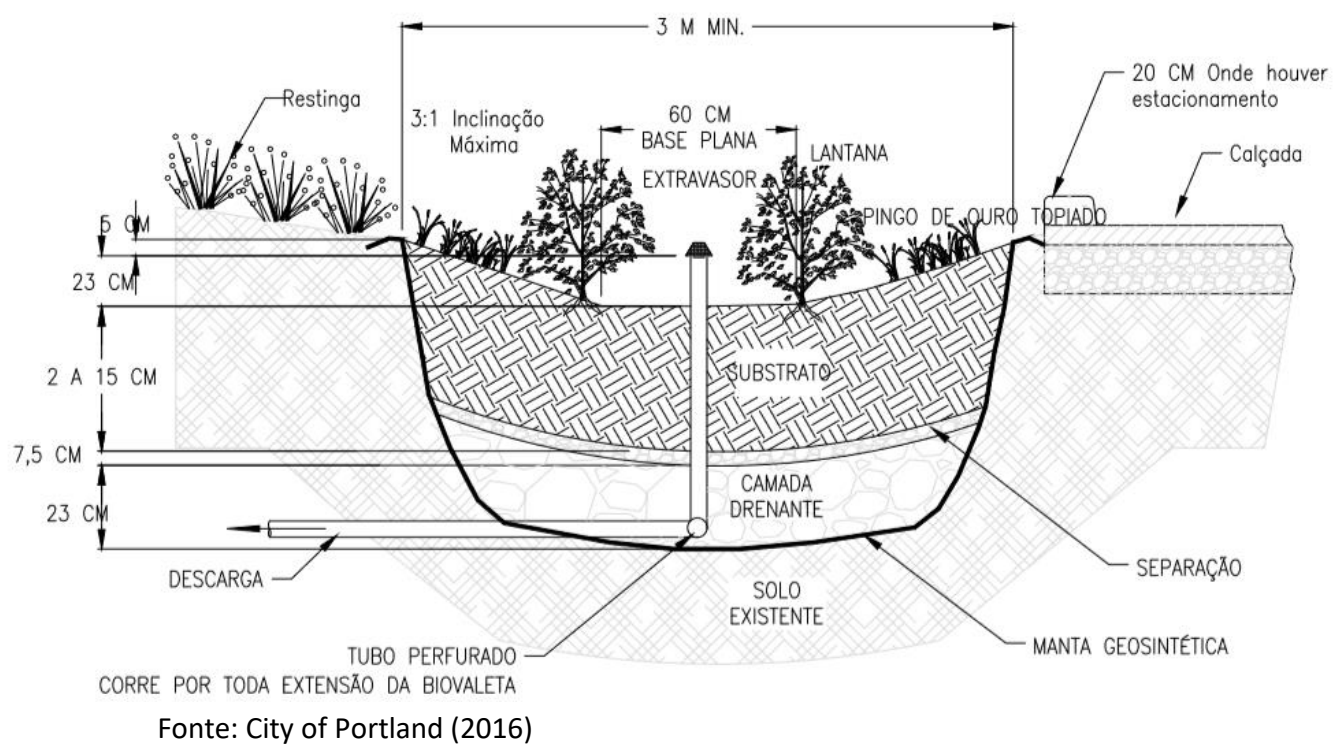

A implantação do projeto contemplou todos os elementos citados, resultando em um projeto completo de caixa de via, a imagem a seguir ilustra a situação: 


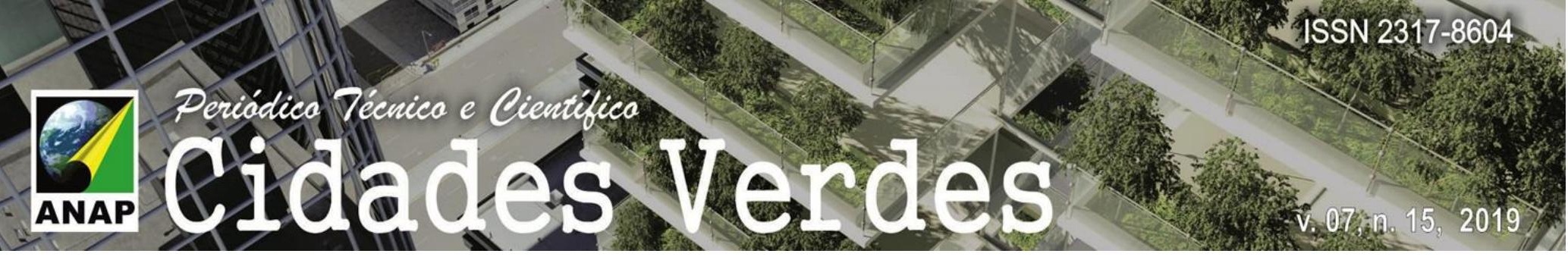

Figura 6 - Ampliação de Meio de Quadra

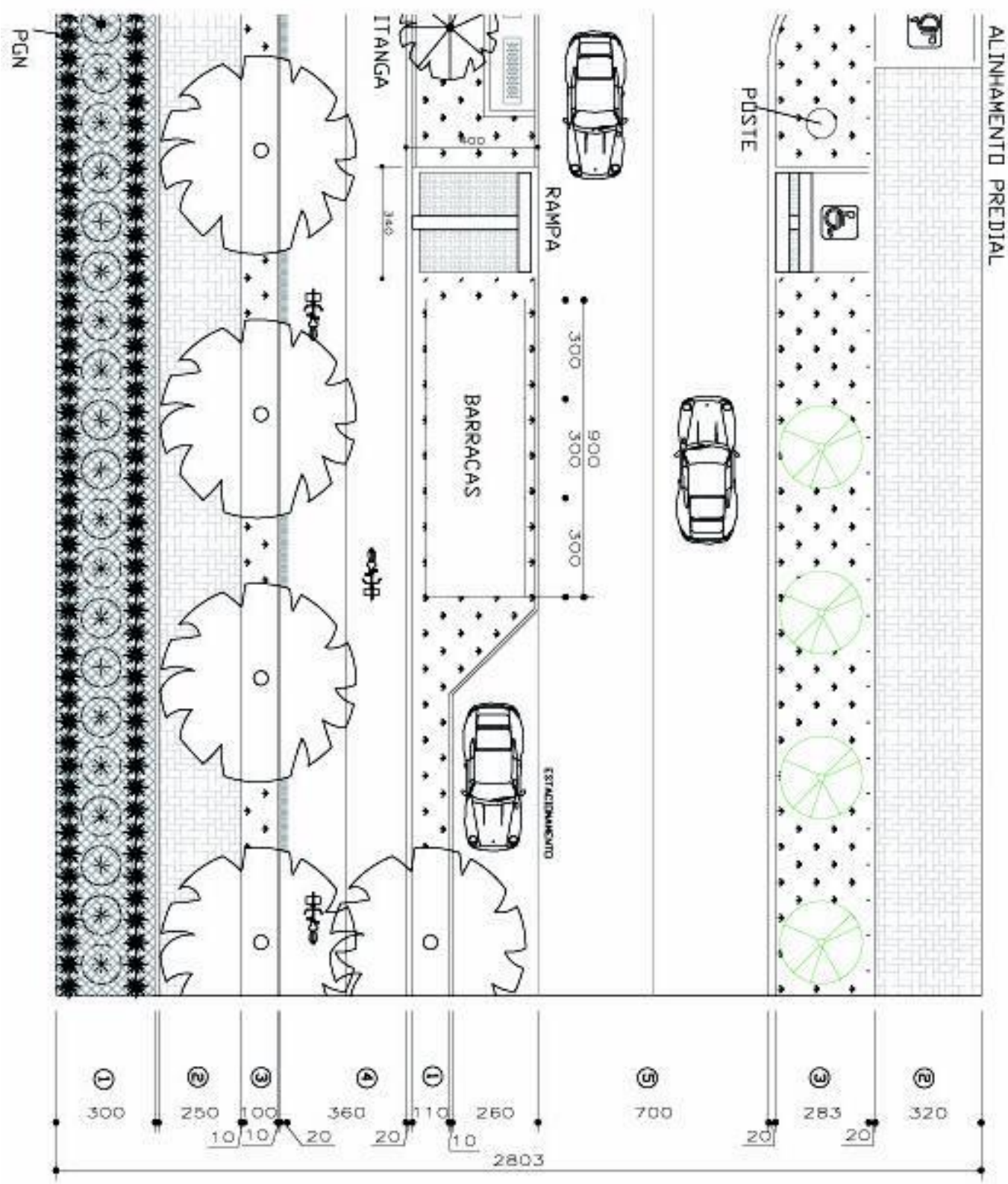

Legenda: 1- Biovaleta, 2- Calçada (piso paver), 3- Jardim gramado, 4 - Ciclovia bidirecional (pav. Concreto), 5- Faixa bidirecional de veículos (pav. Asfáltico).

Fonte: Autores (2018) 


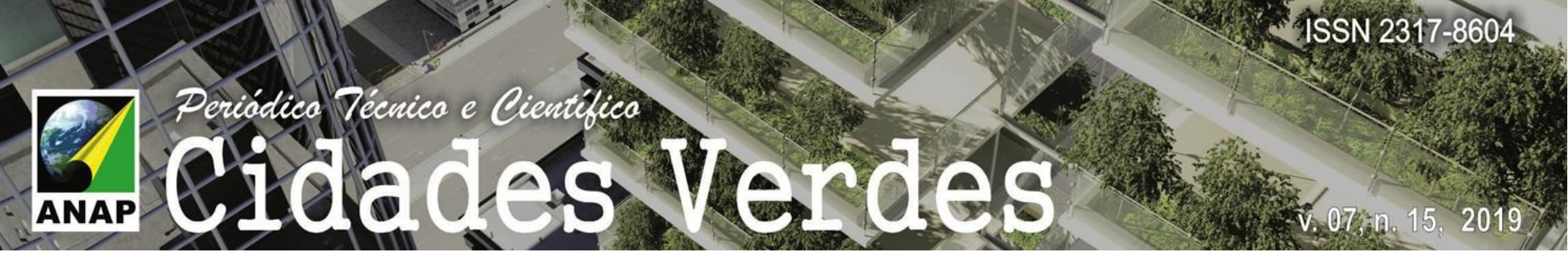

\section{Conclusões}

O projeto da orla de Pontal do Sul foi desenvolvido e coordenado como um projeto de extensão, envolvendo a coordenação da Profa Cintia Miua Maruyama. A baixa infraestrutura existente no local deu possibilidades de execução de vários elementos, como ciclovias, calçadas de pedestres, faixas de vegetação e biovaleta.

Devido à multidisciplinaridade do tema, foi necessárias a junção de conhecimentos de várias áreas e a participação de vários alunos e professores. Neste sentido foi positivo para a formação dos acadêmicos, pois possibilitou rica experiência de aplicação de conhecimentos adquiridos na academia numa experiência real de projeto urbano, além de contato e reflexão com os problemas e possibilidades de soluções da região onde estudam. O projeto será cedido à Prefeitura Municipal de Pontal do Paraná para servir como suporte de projeto para execução em futuras iniciativas municipais na direção do desenvolvimento de infraestrutura local.

A falta de informações precisas por parte da Prefeitura Municipal de Pontal do Paraná dificultou a coleta de dados, e também a definição da largura da seção de via no projeto. Neste sentido, entende-se que a municipalidade necessita criar e administrar dados confiáveis para a execução de projetos, que trarão grande benefício à cidade.

\section{Agradecimentos}

Agradecemos à colaboração dos discentes do curso de Engenharia Civil do da Universidade Federal do Paraná - Campus de Pontal do Paraná: Denise do Prado Mota, Giovanni Carvalho e Karina Ferreira. Também somos gratos à Pro-Reitoria de Extensão e Cultura - PROEC da Universidade Federal do Paraná pelas bolsas de extensão concedidas aos alunos nos anos de 2017 e 2018.

\section{Referências bibliográficas}

BONZI, Ramón Stock. Andar sobre água preta: a aplicação da infraestrutura verde em áreas densamente urbanizadas. Dissertação de Mestrado. Universidade de São Paulo. São Paulo. 2015.

CITY OF PORTLAND. Oregon. Stormwater Management Manual. 2016. Disponível em < https://www.portlandoregon.gov/bes/64040>. Acesso em 01/01/2018.

FRANÇA, Júnia Lessa et al. Manual para normalização de publicações técnico-cientificas. 6. ed. rev. e ampl. Belo Horizonte: UFMG, 2003. $230 p$

GARTLAND, Lisa. Ilhas de calor: como mitigar zonas de calor em áreas urbanas. Oficina de Textos, São Paulo. 2010.

GEIPOT - Empresa Brasileira de Planejamento de Transportes. Manual de planejamento cicloviário. -- 3. ed., rev. e amp. -- Brasília : GEIPOT, 2001. xvii, 126p.: il

IBGE - INSTITUTO BRASILEIRO DE GEOGRAFIA E ESTATÍSTICA, Pesquisa de dados de municípios. Disponível em https://cidades.ibge.gov.br Acesso em 12/02/2019

IPARDES - INSTITUTO PARANAENSE DE DESENVOLVIMENTO ECONÔMICO E SOCIAL. Caderno estatístico do município de Pontal do Paraná. 2019 


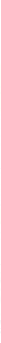

LAKATOS, Eva Maria; MARCONI, Marina de Andrade. Fundamentos de metodologia científica. 3. ed. rev. e ampl. São Paulo: Atlas, 1991. 270 p.

MASCARÓ, Juan Luis; MASCARÓ, Lucia e FREITAS, Ruskin Marinho de. Infra-estrutura da Paisagem. Masquatro Editora. Porto Alegre. 2008

PREFEITURA DE PONTAL DO PARANÁ. Histórico do Município • Disponível em http://www.pontaldoparana.pr.gov.br/. Acesso em 12/02/2019

PORTLAND STORMWATER MANAGEMENT MANUAL - $\quad$ (2016) Disponível em https://www.portlandoregon.gov/bes/71127. Acesso em 12/02/2019

SCHUTZER, J. Infraestrutura Verde No Contexto Da Infraestrutura Ambiental Urbana E Da Gestão Do Meio Ambiente. Revista LABVERDE, (8), 12-30. https://doi.org/10.11606/issn.2179-2275.v0i8p12-30. 2015 